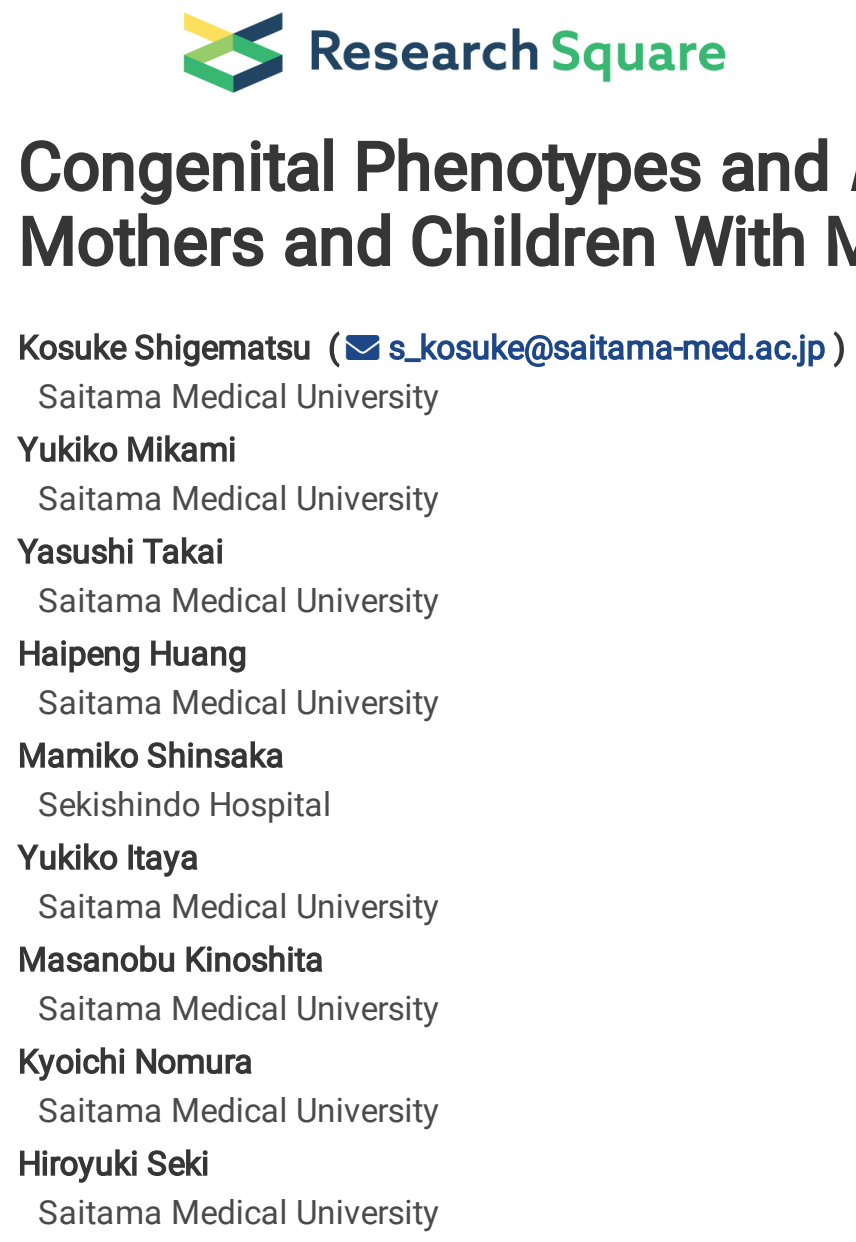

\title{
Congenital Phenotypes and DMPK CTG Repeat Number in Mothers and Children With Myotonic Dystrophy Type 1
}

\section{Research Article}

Keywords: Congenital, DNA Repeat Expansion, Myotonic Dystrophies, Myotonic Dystrophy 1, Pregnancy

Posted Date: April 8th, 2021

DOI: https://doi.org/10.21203/rs.3.rs-395311/v1

License: @ (i) This work is licensed under a Creative Commons Attribution 4.0 International License. Read Full License

Version of Record: A version of this preprint was published at OBM Genetics on March 28th, 2023. See the published version at https://doi.org/10.21926/obm.genet.2301179. 


\begin{abstract}
Myotonic dystrophy type 1 (DM1) is an autosomal dominant genetic disease. In DM1, the mutant allele expands during gametogenesis, and an extended CTG repeat sequence is inherited by the offspring. This often results in increased severity of DM1 symptoms in the affected offspring and may cause congenital myotonic dystrophy (CDM). This study aimed to clarify whether CTG repeat number predicts CDM in offspring. This retrospective study examined 14 women with DM1, their pregnancy and labor histories, and their 14 children diagnosed with DM1. There were 12 CDM patients and 2 non-CDM patients. Correlations between CDM onset and CTG repeat numbers of the mother and child were analyzed. Women who bore a child with CDM (infants with detected polyhydramnios during pregnancy, hypotonia, respiratory insufficiency, or suckling failure at birth) had a mean repeat number of 643 (standard deviation [SD] 436). For women who bore a child without CDM, the mean repeat number was 950 (SD 71), and no significant between-group difference was detected. The mean (SD) CTG repeat numbers observed in children with and without CDM were 1,646 (324) and 1,700 (565), respectively. CDM cannot be predicted based on the CTG repeat numbers of mothers or children.
\end{abstract}

\title{
Introduction
}

Myotonic dystrophy type 1 (DM1) is an autosomal dominant genetic disorder characterized by myotonia and muscular dystrophy. DM1 is a multisystem disorder that affects not only the skeletal muscle, but also the smooth muscle, eyes, heart, endocrine system, and central nervous system. DM1 is caused by the expansion of a CTG repeat sequence present in the 3' untranslated region of the dystrophia myotonica protein kinase (DMPK [MIM: 605377]) gene on chromosome 19. Children of patients who carry the expanded allele have a $50 \%$ chance of inheriting the mutant allele. As the mutant allele expands during the process of gametogenesis, an extended CTG repeat sequence is inherited by the next generation. Furthermore, symptoms of DM1 are known to manifest earlier and with greater severity in children than in a parent ${ }^{1-5}$.

Congenital myotonic dystrophy (CDM) is a clinical form of DM1 that presents as marked muscle weakness from birth ${ }^{6-9}$. It has been reported that $2-55 \%$ of children with DM1 born to mothers with DM1 develop CDM ${ }^{10-12}$. DM1 can be diagnosed prenatally; however, reports on how to predict whether a child may have CDM are scarce. Our hospital is one of the largest Japanese perinatal centers. After several mothers with DM1 delivered at our hospital, we noticed that the CTG repeat lengths of infants did not necessarily reflect disease severity.

Therefore, we hypothesized that it is not possible to predict whether or not infants will develop CDM based on their CTG repeat numbers. This study aimed to clarify whether the CTG repeat number of the mother or her child could be used to predict the development of CDM in the child. To do this, we examined CTG repeat numbers in mothers and their children, pregnancy course, DM1 severity in the mother, and outcomes in children with DM1 borne by mothers with DM1. We also analyzed the prognostic factors associated with CDM risk in children.

\section{Results}

\section{Clinical and demographic characteristics of study participants}

Fourteen mothers and their 14 children were enrolled in the study. Twelve children (86\%) were diagnosed with CDM (CDM group). The other two children (14\%) were diagnosed with DM1 during development (non-CDM group). Characteristics of the enrolled mothers are presented in Table 1. Data regarding the characteristics of the children at their time of birth are presented in Table 2. Cases with the same numbers as shown in Tables 1 and 2 represent the mother and her child, respectively. 
Table 1

Characteristics of maternal participants

\begin{tabular}{|c|c|c|c|c|c|c|c|c|c|}
\hline No. & $\begin{array}{l}\text { CTG } \\
\text { repeat } \\
\text { number }\end{array}$ & $\begin{array}{l}\text { Pregnancy } \\
\text { and labor } \\
\text { history }^{\dagger}\end{array}$ & $\begin{array}{l}\text { Age at } \\
\text { symptom } \\
\text { onset } \\
\text { (years) }\end{array}$ & $\begin{array}{l}\text { Age at } \\
\text { diagnosis } \\
\text { (years) }\end{array}$ & $\begin{array}{l}\text { Age at } \\
\text { childbirth } \\
\text { (years) }\end{array}$ & $\begin{array}{l}\text { Placental } \\
\text { abnormalities }\end{array}$ & $\begin{array}{l}\text { Threatened } \\
\text { preterm } \\
\text { labor }\end{array}$ & PROM & $\begin{array}{l}\text { Cesarean } \\
\text { section }\end{array}$ \\
\hline 1 & 100 & $2 \mathrm{SA}$ & 26 & 37 & 37 & None & Yes & Yes & Yes \\
\hline 2 & 200 & None & 25 & 38 & 38 & None & Yes & Yes & Yes \\
\hline 3 & 600 & $1 \mathrm{SA}$ & 14 & 28 & 27 & None & Yes & None & Yes \\
\hline 4 & 1,000 & None & 25 & 40 & 41 & None & Yes & Yes & Yes \\
\hline 5 & 146 & $1 \mathrm{EP}$ & 30 & 36 & 36 & None & Yes & Yes & Yes \\
\hline 6 & 600 & $1 \mathrm{SA}, 1 \mathrm{EP}$ & 25 & 39 & 39 & Yes & Yes & Yes & Yes \\
\hline 7 & 100 & None & 33 & 34 & 32 & None & None & None & None \\
\hline 8 & 600 & None & 30 & 40 & 40 & None & Yes & Yes & Yes \\
\hline 9 & 1,000 & $1 \mathrm{SA}, 1 \mathrm{~TB}$ & 44 & 49 & 34 & None & None & None & None \\
\hline 10 & 1,370 & 1 TB (id) & 40 & 47 & 23 & None & None & None & None \\
\hline 11 & 1,000 & None & 47 & 55 & 27 & None & None & None & None \\
\hline 12 & 900 & 1 TB & 45 & 48 & 26 & None & None & None & None \\
\hline 13 & 900 & $\begin{array}{l}2 \text { TB (id and } \\
\text { died at the } \\
\text { age of } 9 \\
\text { years }\end{array}$ & 23 & 25 & 24 & None & None & None & Yes \\
\hline 14 & 1,100 & 1 TВ & 28 & 30 & 26 & None & None & None & None \\
\hline \multicolumn{10}{|c|}{${ }^{\dagger}$ except for applicable delivery } \\
\hline
\end{tabular}


Table 2

Characteristics of pediatric participants

\begin{tabular}{|c|c|c|c|c|c|c|c|c|c|}
\hline No & $\begin{array}{l}\text { CTG } \\
\text { repeat } \\
\text { number }\end{array}$ & Diagnosis & $\begin{array}{l}\text { Gestational } \\
\text { weeks at } \\
\text { delivery }\end{array}$ & $\begin{array}{l}\text { Birth } \\
\text { weight } \\
\text { (g) }\end{array}$ & Polyhydramnios & $\begin{array}{l}\text { Respiratory } \\
\text { insufficiency }\end{array}$ & Hypotonia & $\begin{array}{l}\text { Suckling } \\
\text { failure }\end{array}$ & $\begin{array}{l}\text { Current } \\
\text { age } \\
\text { (years; as } \\
\text { of } \\
\text { September } \\
\text { 2020) }\end{array}$ \\
\hline 1 & 1,625 & CDM & 32 & 1977 & Yes & Yes & Yes & Yes & 1 \\
\hline 2 & 1,300 & CDM & 25 & 738 & Yes & Yes & Yes & Yes & 4 \\
\hline 3 & 1,800 & CDM & 35 & 2,654 & Yes & Yes & - & Yes & 5 \\
\hline 4 & 2,100 & CDM & 29 & 1,102 & None & Yes & Yes & Yes & 7 \\
\hline 5 & 1,800 & CDM & 32 & 1,588 & Yes & Yes & Yes & Yes & 10 \\
\hline 6 & 1,600 & CDM & 37 & 2030 & Yes & Yes & Yes & Yes & 9 \\
\hline 7 & 1,000 & CDM & 40 & 3,200 & Yes & Yes & - & Yes & 11 \\
\hline 8 & 1,600 & CDM & 36 & 2,154 & Yes & Yes & Yes & Yes & 12 \\
\hline 9 & 1,500 & CDM & 31 & 1,694 & Yes & Yes & Yes & Yes & 23 \\
\hline 10 & 2,066 & CDM & 40 & 3,400 & Yes & Yes & - & Yes & 34 \\
\hline 11 & 1,300 & DM1 & 40 & 2,900 & None & None & None & None & 36 \\
\hline 12 & 2,100 & DM1 & 39 & 2,180 & None & None & None & None & 37 \\
\hline 13 & 1,966 & CDM & $>37$ & 3,200 & None & Yes & - & - & 37 \\
\hline 14 & 1,400 & CDM & 37 & 2,850 & None & - & - & Yes & $38^{\dagger}$ \\
\hline \multicolumn{10}{|c|}{ tDied at the age of 38 years } \\
\hline \multicolumn{10}{|c|}{ Unknown items are represented by a "-" sign } \\
\hline
\end{tabular}

The mean CTG repeat number (standard deviation, SD) of mothers included in the present study was 686 (417). Mothers were diagnosed with DM1 at the mean age (SD) of 38.9 (8.8) years. No significant correlation between CTG repeat number and age at diagnosis (correlation coefficient $=0.3517, p=0.4997$ ) was observed. Maternal DM1 was diagnosed before pregnancy in one participant, during pregnancy in three participants, and after delivery in 10 participants, and the mean CTG repeat numbers (SD) observed in the corresponding groups were 1,000, 466 (230), and 721 (459), respectively. Correlation analysis revealed no correlation between diagnosis timing and CTG repeat number.

\section{Obstetric complications of CDM and non-CDM groups}

Placenta previa, which is a reported complication of DM1 pregnancies ${ }^{14,15}$, occurred in only one participant (7.1\%). Occurrence of other reported complications was as follows: polyhydramnios in nine participants (64.3\%), threatened premature labor in seven $(50.0 \%)$, premature rupture of membranes in six $(42.9 \%)$, and end of pregnancy due to premature delivery in seven $(50.0 \%)$. The median gestational age at delivery (range) for study participants was 36.5 (25-40) weeks. Polyhydramnios was observed in all participants who experienced the threat of premature labor, although one participant whose pregnancy continued to 40 weeks developed polyhydramnios without symptoms of threatened premature labor.

No significant difference regarding the number of obstetrical complications of mothers of CDM and non-CDM groups was observed. Children in the CDM group were delivered prematurely, but there was no significant difference in the median number of gestational weeks at delivery between the CDM and non-CDM groups (35.5 [25-40] and 39.5 [39-40] weeks, respectively). The mean CTG repeat numbers (SD) identified in mothers of children in CDM and non-CDM groups were 643 (436) and 950 (71), respectively, and 
no significant difference was observed between groups (Table 3). Further, there was no significant difference in maternal age at delivery between the groups, although the mean maternal ages at DM1 symptom onset and diagnosis were significantly higher in the non-CDM than in the CDM group (mean [SD]: age at symptom onset: 28.6 [7.9] vs. 46.0 [1.4] years, $p<0.05$; age at diagnosis: 36.9 [7.1] vs. $51.5[4.9]$ years, $p<0.05$; Table 3$)$.

Table 3

Comparison between the congenital myotonic dystrophy (CDM) group and non-CDM group

\begin{tabular}{|c|c|c|c|}
\hline & $\begin{array}{l}\text { CDM group } \\
(n=12)\end{array}$ & $\begin{array}{l}\text { Non-CDM grou } \\
(n=2)\end{array}$ & \\
\hline Maternal CTG repeat number, times, mean (SD) & $643(436)$ & $950(70.7)$ & N.S. \\
\hline Infant CTG repeat number, times, mean (SD) & $1,646(324)$ & $1,700(565)$ & N.S. \\
\hline Maternal age at symptom onset, years, mean (SD) & $28.6(7.9)$ & $46.0(1.4)$ & $p<0.05$ \\
\hline Maternal age at diagnosis, years, mean (SD) & $36.9(7.1)$ & $51.5(4.9)$ & $p<0.05$ \\
\hline History of spontaneous abortion or infant death ${ }^{\dagger}, \mathrm{n}(\%)$ & $6(50.0 \%)$ & $0(0.0 \%)$ & N.S. \\
\hline Maternal age at delivery, years, mean (SD) & $35(6.24)$ & $26.5(0.5)$ & N.S. \\
\hline Symptoms experienced before pregnancy, n (\%) & $8(66.7 \%)$ & $0(0.0 \%)$ & N.S. \\
\hline Placenta previa, n (\%) & $1(8.3 \%)$ & $0(0 \%)$ & N.S. \\
\hline Hydramnios, n (\%) & $9(75 \%)$ & $0(0 \%)$ & N.S. \\
\hline Treatment for threatened preterm labor, $\mathrm{n}(\%)$ & $7(58.3 \%)$ & $0(0 \%)$ & N.S. \\
\hline Premature rupture of membrane, $\mathrm{n}(\%)$ & $6(50 \%)$ & $0(0 \%)$ & N.S. \\
\hline Gestational age at delivery, weeks, median (range) & $35.5(25-40)$ & $39.5(39-40)$ & N.S. \\
\hline Premature delivery, $\mathrm{n}(\%)$ & $7(58.3 \%)$ & $0(0 \%)$ & N.S. \\
\hline Cesarean section, $\mathrm{n}(\%)$ & $8(66.7 \%)$ & $0(0 \%)$ & N.S. \\
\hline \multicolumn{4}{|l|}{ the patient died at the age of $<1$ year } \\
\hline \multicolumn{4}{|c|}{ Abbreviations: CDM, congenital myotonic dystrophy; n, number (\%); SD, standard deviation; N.S., not significant } \\
\hline \multicolumn{4}{|c|}{$\begin{array}{l}\text { The Student's t-test was performed for analyzing maternal/infant CTG repeat number, maternal age at symptom } \\
\text { onset/diagnosis, and maternal age at delivery. }\end{array}$} \\
\hline \multicolumn{4}{|c|}{ The Mann-Whitney U test was performed for analyzing gestational weeks at delivery. } \\
\hline $\begin{array}{l}\text { The chi-square test was performed for comparing the } \mathrm{p} \\
\text { of symptoms before pregnancy, placenta previa, hydrar } \\
\text { membrane, premature delivery, and cesarean section. }\end{array}$ & $\begin{array}{l}\text { ory of spontar } \\
\text { for threatened }\end{array}$ & $\begin{array}{l}\text { abortion or infa } \\
\text { ture labor, prem }\end{array}$ & $\begin{array}{l}\text { experience } \\
\text { ture of }\end{array}$ \\
\hline
\end{tabular}

\section{Outcomes in children of CDM and non-CDM groups}

The mean numbers of CTG repeats (SD) observed for children in the CDM and non-CDM groups were 1,646 (324) and 1,700 (565), respectively, and no statistically significant difference between the groups was observed. The most common symptoms in children with CDM were respiratory insufficiency and suckling failure, which were observed in 11 children (92\%). This was followed by polyhydramnios and hypotonia, which were observed in nine (75\%) and seven (58\%) children, respectively.

Results of the multivariate analysis of factors associated with CDM in children are presented in Table 4. The threshold for maternal age at DM1 symptom onset associated with CDM in children was 44 years, which was calculated based on a receiver operating characteristic curve. Multivariate analysis revealed that a maternal age at symptom onset of $\leq 44$ years was the only significant risk factor for CDM in children. 
Table 4

Multivariate analysis of factors associated with congenital myotonic dystrophy

\begin{tabular}{|llll|}
\hline Factor & Odds ratio & $95 \%$ confidence interval & p-value \\
\hline Maternal age at symptom onset, $\leq 44$ years & $7.78 \times 10^{21}$ & 14.168 to inf. & $<0.05$ \\
\hline Maternal CTG repeat number & 1.000 & 0 to $3.7 \times 10^{194}$ & N.S. \\
\hline Infant CTG repeat number & 1.000 & 0 to $1.5 \times 10^{232}$ & N.S. \\
\hline Abbreviations: N.S., not significant & & & \\
\hline
\end{tabular}

An examination of the clinical course of offspring after childhood demonstrated that symptoms of DM1 emerged with increasing age even in those without CDM, and the individuals eventually exhibited motor and neurodevelopmental disorders. One participant died at the age of 38 years, but other included individuals are currently outpatients (median age as of September 2020, 11.5 [range: $1-38$ ] years).

\section{Discussion}

To the best of our knowledge, this is the largest study in Japan to assess mothers and children who were both diagnosed with DM1. Similar studies of this scale are rare, even outside of Japan. In this study, no significant correlation was found between the number of CTG repeats in mothers and their children, and the presence of a high number of repeats did not lead to an early diagnosis of CDM. However, age at symptom onset and age at diagnosis were significantly higher in mothers of children in the non-CDM group. Therefore, study findings revealed important information regarding pregnancy, childbirth, neonatal management of women with DM1, and the suitability of prenatal diagnosis in pregnant women with DM1, despite the limited number of study participants.

DM1 severity is commonly correlated with the number of CTG repeats present in the DMPK gene ${ }^{16}$. CDM is considered an earlyonset and severe form of DM1 1,2,16. However, no significant increase in the CTG repeat number was observed among children with CDM relative to that observed in those without CDM. The lack of difference between children with and without CDM may have been due to the small number of children without CDM included in the study. Further, the two individuals without CDM were determined to have relatively severe DM1 because they presented DM1 symptoms during childhood, which may have affected the results. In fact, the children in this study had a CTG repeat number of $\geq 1,000$. The absence of clear diagnostic criteria for CDM may also have influenced findings ${ }^{13}$.

The proportion of children with CDM versus DM1 in this study was greater than those reported previously ${ }^{10-12}$. We believe that this difference may be due to the factors such as serious cases of DM1 are easier to diagnose than milder cases, the absence of paternally inherited cases in this study, and the absence of established diagnostic criteria for CDM.

An investigation of characteristics of mothers revealed no significant correlation between CTG repeat number and age at diagnosis, which indicated that elevated repeat numbers did not result in an earlier diagnosis. This may be because the timing of DM1 diagnosis was influenced not only by the severity of symptoms but also by how individuals perceived the disease. The significantly younger age at diagnosis among mothers whose children had CDM was probably influenced by the diagnosis of the child, which in turn prompted physicians to establish a diagnosis for the mother. In cases of DM1, patients with mild symptoms tended to have delayed diagnoses ${ }^{17}$. Particularly in women, DM1 is often associated with infertility, abnormalities during pregnancy, miscarriage, and premature delivery ${ }^{13,17-21}$, hence, obstetricians and gynecologists must be aware that obstetric consultations may potentially lead to a DM1 diagnosis.

Japanese cases of polyhydramnios during pregnancy or threatened preterm labor that led to a diagnosis of DM1 have been reported 20,22 . However, the results of our study revealed that it is difficult to predict whether fetuses would present with CDM in cases without polyhydramnios despite being diagnosed with DM1 based on the expanding CTG repeat number. However, our study did reveal that a young maternal age at symptom onset may be a risk factor for the occurrence of CDM. Therefore, a reduction in CDM risk may be possible to predict when the pregnant mother has not yet developed DM1 symptoms. 
Barbé et al. suggested that high levels of methylation upstream and downstream of the CTG repeat were better correlated with CDM onset than the CTG repeat number itself ${ }^{23}$. We anticipate that the development of testing strategies other than CTG repeat number will be necessary for identifying predictors of DM1 severity in children ${ }^{24,25}$. In our study, CTG repeat numbers were higher in all children than their corresponding mothers, and symptoms were more severe in children than in mothers. However, no children died during infancy, and life expectancy was better than that expected based on previous reports $1,2,6,13,18$. The small number of cases and large time gaps between births in our study prevented a detailed statistical analysis of long-term prognoses among pediatric participants. In addition, clinical features during early infancy and thereafter varied greatly between individual cases regardless of CDM diagnosis. Therefore, we cannot assert that there is no hope of long-term survival for children diagnosed with CDM, as has been indicated in prior reports. Our study has several limitations, including its single-center retrospective design and disproportional participant composition (primarily patients with CDM). Additional multicenter studies with larger cohorts are needed.

The tendency of patients with mild symptoms to be overlooked, rather than diagnosed with DM1, may have affected the findings of this study. In particular, this study may have included patients with relatively severe disease, which may have affected our statistical analysis. Therefore, some of the results of this study, especially the proportion of infants with CDM, may not be valid for all DM1 groups. However, even among cases of severe DM1, no children died during infancy. This result indicates that high repeat numbers do not guarantee early mortality.

The findings of our study suggest that even when the CTG repeat number of the fetus is determined by prenatal genetic testing, extreme care must be taken when using this information to determine the future of the pregnancy. Multiple articles have already reported difficulties associated with prenatal genetic testing for $\mathrm{DM} 1{ }^{26}$, and our study supports the findings of prior authors. Affected mothers and families should be provided accurate information derived from the latest available evidence and given broad support, not only from obstetricians but also from clinical genetic specialists including genetic counselors, pediatricians, and neurologists to make informed independent decisions.

\section{Methods}

This retrospective study included Japanese patients with DM1 who visited the department of neurology at Saitama Medical Center, Saitama Medical University, between November 2017 and August 2019. We selected 14 mothers and infants who attended the center and agreed to participate in the study. Of these individuals, the mothers had received diagnosis of DM1 and infants were born with DM1. Women aged 20-70 years with a history of pregnancy and labor and their children with DM1 were selected as participants. The methodology of this study was explained to the adult participants, and written voluntary consent was obtained. For study participants unable to provide consent, as a result of being a minor or due to the effects of DM1, the study plan was explained to a dependent, parent, or child (provided the dependent, parent, or child was at least 20 years old) before the enrollment of participants who provided consent by proxy. Further, informed consent was obtained from the parent or legal guardian, if the participant was a minor. Only those who provided written consent via any of the aforementioned methods were enrolled in the study. The study protocol was approved by the ethical committee (IRB no. 1741-IV) of Saitama Medical Centre of Saitama Medical University, and the study was performed in accordance with the principles of the Declaration of Helsinki.

Information about mothers and children was obtained from medical records and questionnaires. For mothers, data regarding the age at DM1 symptom onset and diagnosis, CTG repeat number, details of their pregnancy and labor history (including obstetrical complications [Yes/No], obstetrical abnormalities [Yes/No], delivery mode, placental abnormalities [Yes/No], and threatened preterm labor [Yes/No] [defined as threatened preterm labor appearing in medical records or diagnosed as preterm labor by the attending physician]) were collected. For children, information regarding gestational age at delivery, birth weight, birth and the neonatal period, course of motor development, and CTG repeat number was collected.

If study participants had not previously undergone a CTG repeat number test, they were tested after providing consent. In participants who underwent CTG repeat number testing at another facility, consent was obtained from the participant or an adult family member in writing before information was requested from the facility. Further, when adequate medical information could not be obtained from questionnaires, more information was requested from other medical facilities that provided medical care to participants after written consent was obtained. Given the absence of clear CDM diagnostic criteria, CDM was defined as the 
presence of the following symptoms: polyhydramnios in pregnancy, hypotension, respiratory failure, or inadequate lactation at birth, as described in other reports ${ }^{13}$.

To clarify the clinical characteristics of children diagnosed with CDM, the participants were divided into two groups (with and without CDM). A Student's t-test was used to compare the mean values between groups, and the Mann-Whitney Utest was used to compare the median gestational weeks at delivery. Proportions of patients were compared using a chi-square test. Correlation analyses were performed to examine correlations between CTG repeat number and maternal age at symptom onset and diagnosis. Multivariable analysis was performed to assess prognostic factors associated with CDM in children with data available before 22 weeks of gestation, the legal gestational age for the termination of pregnancy in Japan. Candidate factors included maternal age at symptom onset ( $\leq 44$ years) and maternal and infant CTG repeat numbers. Receiver operating characteristic curves were drawn using sensitivity and specificity values, with CDM in the child as the target variable and maternal age as a factor. The cutoff value for maternal age was determined to be 44 years based on its Youden index. Statistical analyses were performed with the JMP, version 14.3.0, software (SAS Institute Inc., Cary, NC, USA). P-values $<0.05$ were considered statistically significant.

\section{Declarations}

\section{Data availability}

The data that support the findings of this study are available from the corresponding author, upon reasonable request.

\section{Acknowledgements}

We would like to thank Editage for English language editing.

\section{Author contributions}

"SK and MY and TY wrote the main manuscript text and HH prepared tables 1-4.

SM and IY collected the data and SK and IY performed data analysis.

All authors reviewed the manuscript."

\section{Competing interests}

The authors declare no conflict of interest.

\section{References}

1. Kamsteeg, E. J. et al. Best practice guidelines and recommendations on the molecular diagnosis of myotonic dystrophy types 1 and 2. J. Hum. Genet. 20, 1203-1208 (2012).

2. Johnson, N. E. \& Heatwole, C. R. Myotonic dystrophy: from bench to bedside. Semin. Neurol. 32, 246-254 (2012).

3. Khan, Z. A. \& Khan, S. A. Myotonic dystrophy and pregnancy. J. Pak. Med. Assoc. 59, 717-719 (2009).

4. Prendergast. P., Magalhaes, S. \& Campbell, C. Congenital myotonic dystrophy in a national registry. Paediatr. Child Health. 15, 514-518 (2010).

5. Campbell, C. Congenital myotonic dystrophy. J. Neurol. Neurophysiol. 01, 10.4172/2155-9562.S7-001 (2012).

6. Turner, C. \& Hilton-Jones, D. The myotonic dystrophies: diagnosis and management. J. Neurol. Neurosurg. Psychiatry. 81, 358367 (2010).

7. Johnson, N. E. et al. Disease burden and functional outcomes in congenital myotonic dystrophy: a cross-sectional study. Neurology. 87, 160-167 (2016).

8. Bosemani, T. et al. Neonatal neuroimaging findings in congenital myotonic dystrophy. J. Perinatol. 34, 159-160 (2014).

9. Shichiji, M. et al. A Japanese nationwide survey on congenital myotonic dystrophy. Neuromuscul. Disord. 26, S196 (2016). 
10. Campbell, C., Levin, S., Siu, V. M., Venance, S. \& Jacob, P. Congenital myotonic dystrophy: Canadian population-based surveillance study. J. Pediatr. 163, 120-125 e121-123 (2013).

11. Campbell, C., Sherlock, R., Jacob, P. \& Blayney, M. Congenital myotonic dystrophy: assisted ventilation duration and outcome. Pediatrics, 113, 811-816 (2004).

12. Lagrue, E. et al. A large multicenter study of pediatric myotonic dystrophy type 1 for evidence-based management. Neurology. 92, e852-e865 (2019).

13. Dorcier, L. M., Coatleven, F., Madar, H. \& Sentilhes, L. Abnormally invasive placentation in a woman with congenital myotonic dystrophy. Int. J. Gynaecol. Obstet. 140, 376-377 (2018).

14. Awater, C., Zerres, K. \& Rudnik-Schoneborn, S. Pregnancy course and outcome in women with hereditary neuromuscular disorders: comparison of obstetric risks in 178 patients. Eur. J. Obstet. Gynecol. Reprod. Biol. 162, 153-159 (2012).

15. Overend, G. et al. Allele length of the DMPK CTG repeat is a predictor of progressive myotonic dystrophy type 1 phenotypes. Hum. Mol. Genet. 28, 2245-2254 (2019).

16. Ho, G., Cardamone, M. \& Farrar, M. Congenital and childhood myotonic dystrophy: Current aspects of disease and future directions. World. J. Clin. Pediatr. 4, 66-80 (2015).

17. Meola, G. Clinical aspects, molecular pathomechanisms and management of myotonic dystrophies. Acta. Myol. 32, 154-165 (2013).

18. Rudnik-Schoneborn, S. \& Zerres, K. Outcome in pregnancies complicated by myotonic dystrophy: a study of 31 patients and review of the literature. Eur. J. Obstet. Gynecol. Reprod. Biol. 114, 44-53 (2004).

19. Johnson, N. E. et al. The impact of pregnancy on myotonic dystrophy: A registry-based study. J. Neuromuscul. Dis. 2, 447-452 (2015).

20. Yee, C. et al. Clinical characteristics of pregnancies complicated by congenital myotonic dystrophy. Obstet. Gynecol. Sci. 60 , 323-328 (2017).

21. Endo, T. et al. A myotonic dystrophy 1 patient complicated with placental adherence after miscarriage of one dichorionic diamniotic twin following her tenth in vitro fertilization and embryo transfer. Arch. Gynecol. Obstet. 286, 1605-1608 (2012).

22. Shin, Y. J. et al. Myotonic dystrophy diagnosed during the perinatal period: A case series report. J. Genet. Med. 13, 105-110 (2016).

23. Barbé, L. et al. CpG methylation, a parent-of-origin effect for maternal-biased transmission of congenital myotonic dystrophy. Am. J. Hum. Genet. 100, 488-505 (2017).

24. López Castel, A., Overby, S. J. \& Artero, R. MicroRNA-based therapeutic perspectives in myotonic dystrophy. Int. J. Mol. Sci. 20, 5600 (2019).

25. Lanni, S. \& Pearson, C. E. Molecular genetics of congenital myotonic dystrophy. Neurobiol. Dis. 132, 104533 (2019).

26. Savić Pavićević, D. et al. Molecular genetics and genetic testing in myotonic dystrophy type 1. Biomed. Res. Int. 2013, 391821 (2013). 